\title{
Five Guiding Principles to Enhance Community Participation in Humanitarian Engineering Projects
}

\author{
Andrea Mazzurco \\ Faculty of Science, Engineering, and Technology, \\ Swinburne University of Technology, Hawthorn, VIC, Australia \\ a.mazzurco@uq.edu.au \\ Brent K. Jesiek \\ School of Engineering Education, \\ Purdue University, West Lafayette, IN, United States \\ bjesiek@purdue.edu
}

\begin{abstract}
Humanitarian engineering (HE) is a very complex endeavour that requires addressing technical problems whilst concurrently engaging the community members who will ultimately benefit from the engineers' solutions. Community participation is particularly important because it is directly linked to the sustainability of projects. Whilst many strategies have been proposed to engage partner communities, the HE literature lacks a comprehensive framework of guiding principles for more effectively engaging community members. The goal of this study is to develop a framework of principles that can support humanitarian engineering professionals and educators to enhance the participation of community members. In this study, we used a qualitative systematised literature review to collect 49 journal articles focused on humanitarian engineering projects and strategies. The analysis of the collected papers led to identification of five guiding principles: 1) collaborating with local champions (NGOs and similar), 2) harnessing local resources and expertise, 3) integrating ethics and social justice, 4) building trusting and equitable relationships, and 5) creating competent multi or inter-disciplinary teams. The identified principles provide a framework that can enable humanitarian professionals and educators involved in small-scale HE projects to enhance the way they interact with community members. We conclude the paper with a series of questions based on the five principles that may allow humanitarian engineers to reflect on the way they interact with community members and thus enhance their relationships. We also invite other humanitarian engineers to further expand concepts related to the suggested principles, and to explore ways to best apply these principles in practice.
\end{abstract}

KEYWORDS: guiding principles, community participation, qualitative systematised literature review

\section{1}

\section{INTRODUCTION}

On his first assignment in Kenya, Mattias was working on energy efficient stoves that would reduce firewood consumption by about $50 \%$. He had found out about solar cookers and thought that this solution would be even better because it would completely eliminate firewood consumption. However, one day whilst he was camping, the locals physically threatened him for cooking outside. Consequently, he realised that open-air cooking is not culturally appropriate in many rural Kenyan communities. Mattias stopped pursuing his solar cooking idea after suddenly realising that it was not an acceptable technology for rural Kenyans (Goldmann, 2012).
The preceding short case study and many similar cases (see Mazzurco and Jesiek, 2014) illustrate the dangers of not engaging meaningfully with communities when working on humanitarian engineering projects. Indeed, many scholars have discussed the importance of meaningful community participation in humanitarian engineering and similar projects (Lissenden, Maley, Mehta, 2015; Mattson and Wood, 2014; Mitcham and Munoz, 2010; Schneider, Leydens, and Lucena, 2010; Vandersteen, Baillie, and Hall, 2009). Whilst other disciplines engaged in international development have long discussed community participation, HE is an emerging field that requires its own guidelines. Yet HE literature still lacks a comprehensive framework that provides guidelines that can enable 
humanitarian engineers and educators to engage more effectively with community members. The lack of such a framework might leave issues related to community participation understudied and/or perceived pertinent only to non-engineering disciplines.

To address this gap, we have undertaken a research project with three main goals: 1) identifying principles that can enable meaningful community participation, 2) classifying design methods that allow community members to influence engineered solutions, and 3) investigating the experiences of humanitarian engineers to provide lessons learned and real-life examples of their partnerships with community members (Mazzurco, 2016; Mazzurco \& Jesiek, 2017). This paper reports results from the first phase of the research project that aimed to create a framework of principles by integrating findings from the extant HE literature.

\section{PROJECT BACKGROUND}

To identify principles, we undertook a qualitative systematised literature review (Grant and Booth, 2009). Following recommendations by Borrego, Foster and Froyd (2014), the search and selection process was adapted from PRISMA (Liberati et al., 2009) and included four main steps: 1) database search, 2) title screening, 3) abstract screening, and 4) full text appraisal. Then, we analysed the collected papers using a qualitative content analysis approach (Hsieh and Shannon, 2005). Whilst the full details of the process are available elsewhere (Mazzurco, 2016), in the next sections we give a concise overview of the four search and selection process steps (sections 2.1 to 2.4), we discuss issues related to reliability of our process (Section 2.5), and summarise the qualitative content analysis approach used to analyse the papers and develop the final framework (Section 2.6).

\subsection{Database Search}

The first author searched for relevant papers in the Compendex and Inspect databases using the Engineering Village search platform. To make sure to include only more contemporary literature, we decide to focus on literature published no earlier than the 1990s. Specifically, we choose 1992 as the starting date because it was when the second Engineers Without Borders (EWB) chapter in Europe was created (the first being in 1982 in France) (Paye, 2010; Canavate \& Casasus, 2010). The literature is limited to an end date of August 2015, as this is when the search was conducted. Additionally, we limited the search to the text of titles and abstracts only, and not the whole papers. To ensure a higher quality of collected sources, only peer-reviewed journal papers were included. The first author utilised 47 search strings and obtained 1,448 candidate articles; example search strings included: "appropriate technology," "humanitarian engineering," and "engineering" and "community development."

\section{$2.2 \quad$ Title Screening}

The goal of this step was to eliminate duplicate references and papers that were outside the scope of the project. The first author discarded 314 duplicates. As we were interested only in small-scale humanitarian engineering projects and in particular the social aspects of such projects, we discarded papers that focused on: 1)technologies or technical aspects only, 2) large-scale projects (e.g., from large international development organisations), 3) non-engineering humanitarian projects (e.g., healthcare, resource management, and others), 4) educational research (e.g., curriculum development and effect on students), and 5) natural disasters and emergency relief. In instances where the title was not clear, the first author decided to keep the papers for the abstract screening step. This process led us to exclude 934 papers and retain 200.

\subsection{Abstract Screening}

The first author read the abstracts of the 200 papers that passed the title screening and again applied the five aforementioned criteria, resulting in another 145 papers to be discarded. At this point, the first author also added 26 papers from the International Journal of ServiceLearning in Engineering and the Journal of Humanitarian Engineering that were not indexed in the Compendex database. Consequently, the first author was left with 81 candidate papers for the final step of full-text appraisal.

\subsection{Full-Text Appraisal}

Finally, the first author read the full text of the remaining 81 papers and discarded those that did not provide any insight regarding interactions between community members and humanitarian engineers. This led us to drop another 32 papers and keep 49 for qualitative content analysis. The final set of papers included both theoretical discussions of humanitarian engineering and numerous case studies situated in a variety of national and cultural contexts.

\subsection{Reliability of Selection Process}

To ensure the selection process described above was reliable, at each stage the first author asked two research colleagues to apply the same approach, as suggested in Borrego et al. (2014). First, the first author gave titles of 50 randomly selected papers to the two research colleagues for review and asked them to independently decide whether to keep the papers or discard them based on the aforementioned criteria. Once they finished, the first author calculated Cohen's kappa $(\kappa)$ to assess Inter-Rater Reliability (IRR). Cohen's $\kappa$ between rater 1 and the first author was 0.65 (substantial agreement 
based on Landis and Koch (1977)), and 0.79 (substantial agreement) between rater 2 and the first author. The first author met with the two colleagues to discuss disagreement, which then led to further clarification of selection criteria. Second and lastly, the author gave the two colleagues 20 randomly selected abstracts for review. They rated the abstracts independently and sent their results to the first author who again calculated Cohen's $\kappa$. The results were Cohen's $\kappa$ of 0.68 with rater 1 and 0.79 with rater 2 (substantial agreement for both). Again, the first author met with the two raters and discussed disagreements and made further clarifications. This reliability process allowed us to strengthen the trustworthiness of the results. The numbers related to selected/excluded articles at each stage that we reported in the previous sections refer to post-IRR procedures.

\subsection{Qualitative Content Analysis}

To analyse and synthesise the final collection of 49 papers, we followed an inductive qualitative content analysis approach that Hsieh and Shannon (2005) define as "a research method for the subjective interpretation of the content of text data through the systematic classification process of coding and identifying themes or patterns" (p. 1278). First, we analysed the content of the collected papers and inductively developed an initial codebook comprised of 98 specific codes. We then re-arranged and merged the 98 codes into 14 overarching themes. We used the 14 themes to run a second analysis of the papers and then made further refinements to the themes. Finally, after further iterations, we looked for commonalities amongst the themes and merged them to obtain our framework of five guiding principles. This process also led us to develop an initial classification of design methods, as presented in more detail in related publications (Mazzurco, 2016; Mazzurco \& Jesiek, 2017).

\section{3}

\section{FINDINGS}

All the collected journal papers discussed the importance of community participation in $\mathrm{HE}$ or similar projects. They all recognised that lack of community participation has led to project failure, and therefore community participation and buy-in is a critical and essential factor of successful HE and similar projects. For instance, in Garfi and Ferrer-Mati's (2011) project evaluation framework, "community participation and access" is one key criterion to evaluate the effectiveness of a project. Moreover, many papers suggest that involvement of community members in every stage of a project leads to a greater sense of community ownership, which is directly linked with the long-term sustainability of solutions.

Every one of the 49 journal articles also described at least one principle that could guide engineers to facilitate community participation in HE projects. Specifically, we identified five guiding principles: 1) collaborating with local champions, 2) harnessing local resources and expertise, 3) integrating ethics, human rights, and social justice, 4) building trusting and equitable relationships, and 5) creating multi or inter-disciplinary and competent teams.

\subsection{Principle 1: Collaborating with local champions}

About half of the papers $(n=26)$ mentioned that collaborating with a partner on-the-ground who is committed to both the community and the project, is one of the best ways to make sure that community members are appropriately involved and represented in the projects. A committed local partner can "play an integral role in facilitating communication and a common language and understanding between the parties based on their deeper knowledge of the local culture" (Chisolm et al., 2014). In her analysis of the winning projects from the first five MIT IDEAS Competitions (an annual competition run by the Massachusetts Institute of Technology (MIT) that awards prizes to student teams that have created solutions for underserved communities), Jue (2011) similarly observed that "collaborating with a solid community partner" was one of six factors for the sustainability of any solution. For instance, she found that:

"the technology created through the Innovative Drinking Water Project is still being disseminated by the project's community partner, a scientific nongovernmental organisation, even though the student team leader left the country, and Nepal's political situation prevented new students from coming into the country" (Jue, 2011, p. 26).

Therefore, the committed project partner ensured the long-term success of the technology even if the student team was not able to go back to the country where they initially implemented the solution.

In contrast, Jue (2011) observed that projects that had unstable project partners or no partner were not sustainable and quickly ended. For instance, she shared the example of a student team that developed an automated early warning system that monitored the river and weather conditions in a small region of Honduras. A reason that the project was not successful in the long run was that the team collaborated with an organisation that had internal issues. The internal issue of the project partner led to the resignation of one leader of the partner organisation, who was also the main contact and the champion for the student team. The person who took the place of the project champion was not as committed to the project as the previous leader, and the student team lost the support that was needed to continue the project.

In line with Jue's (2011) suggestion, we found that the authors of the articles have worked and/or suggested collaborating with a wide range of partners. For 
instance, Aslam et al. (2014), Barb and Everett (2014), and Osnes (2013) collaborated with Peace Corps Volunteers, who were located in the communities where the projects were undertaken. Many papers also cited local and international non-governmental organisations (NGOs) as prospective partners (Aslam et al., 2013; Bowen \& Acciaioli, 2009; Chisolm et al., 2014; Dodson and Bargach, 2015; Ferrer-Marti et al., 2010; Harshfield et al., 2009; Magee et al., 2011; Mattson and Wood, 2014; Third et al., 2009). In addition to NGOs, engineers could collaborate with existing local committees, cooperatives, or governing bodies (Aslam, 2014; Barb and Everett, 2014; de Chastonay et al., 2012; Heil et al., 2010; Marsolek et al., 2012), local universities (Harshfield et al., 2009; Magoon et al., 2010), or individual community members, such as health workers (Barb and Everett, 2014). The key is to find local gatekeepers that can provide access to the community, broker relationships, and support the project whilst the foreign engineers or other professionals are not in the country (Mehta and Mehta, 2011; Parson, 1996; Sianipar et al., 2013).

Sometimes, supporting organisations might also be created in addition to the existing ones. For instance, Ferrer-Mati et al. (2010) facilitated the establishment of a micro-enterprise comprised of community residents to take over operation and maintenance of a small-scale wind generation project for rural electrification in Peru. Similarly, Munoz (2014), with the help of a local social scientist in a small village in Honduras, encouraged the creation of "circles of friends", small groups of local women who got together to embark on small projects, some of which became micro-enterprises. The creation of small groups not only ensures that systems can be maintained, but also helps build local capacity and interdependency in the host community.

\subsection{Principle 2: Harnessing Local Resources and Expertise}

Another large set of papers $(n=34)$ discussed the importance of harnessing the existing natural and human resources available in the community. As Murphy et al. (2009) observe, "a tool made from local materials by local tradesman will likely be more affordable and sustainable than an imported tool from the developed world" (p. 160). To reflect this principle, Garfi and Ferrer-Mati's (2011) decision-making framework for selecting appropriate technology considers the percentage of local materials and resources used in developing technologies as a decisive indicator to assess the potential success and sustainability of a solution. One specific strategy to identify local resources and materials is that of surveying local stores and vendors (Aslam et al., 2014; Barb and Everett, 2014; Magoon et al., 2010; Nieusma and Riley, 2010).

Looking beyond materials, the most important resource of a community is its people. Mattson and Wood (2014) encourage designers to recognise that "resource-poor individuals have valuable expertise in surviving in low resource environments and in understanding local materials and networks" (p. 2). Similarly, McDaniel et al. (2011) observed that the community where they were working did not have extensive financial capital, but was rich with local technical experts, such as bricklayers, carpenters, and other specialised construction workers. It is indeed common that engineers and designers harness such local expertise. For instance, de Chastonay et al. (2012) collaborated closely with rural South African brick makers who "mastered the creation of insulating bricks" (p. 59). Similarly, Hussain and Sanders (2012) worked with a local sculptor to "develop models of feet in clay" of prosthetic legs for underserved Cambodian children. To make sure that local expertise was properly integrated in the project, Ramirez et al. (2011) invited some community members to be part of the design team. Thus, harnessing local expertise and resources is a fundamental guideline to any humanitarian engineering or similar project.

\subsection{Principle 3: Integrating Ethics and Social Justice}

Many papers $(n=21)$ advised that engineers need to consider issues related to ethics and social justice. For instance, engineers need to think about the ethical issues related to doing research with people in developing countries (Hinton et al., 2014). To make sure that they were adhering to proper ethical standards related to research, Aslam et al. (2014), de Chastoney et al. (2012), Harshfield et al. (2009), and Magoon et al. (2010) followed accepted guidelines and protocols for research with human subjects, including by securing appropriate approvals (e.g., via an institutional review board or similar body). This is particularly important because distrust between engineers and communities can be generated when ethical issues are not taken into account (Hinton et al., 2014).

In addition, Amadei et al. (2009) state that engineers are always "bound to a professional code of ethics with regard to behaviour, accountability, quality control and quality assurance, and delivery of projects" (p. 1094). However, professional codes of ethics provide useful, but limited ethical guidelines (Leydens and Lucena, 2014). To be able to collaborate fully and effectively with community members, engineers need to consider social justice issues (Vandersteen et al., 2009). With social justice as the aim, some papers suggested addressing the effect of root causes and structural conditions of problems in communities (Amadei et al., 2009; Leydens and Lucena, 2014; Nieusma and Riley, 2010; Parson, 1996), such as "economic, cultural, or other conditions that enable or constrain community aspirations" (Leydens \& Lucena, 2014, p. 9). Others also recognised the importance of mitigating power differentials between engineers and community members (Hinton et al., 2014; Leydens and Lucena, 2014; Murphy et al., 2009; Nieusma and Riley, 2010), respecting human 
rights (Byars et al., 2009; Bowen and Acciaioli, 2015), increasing opportunities, mitigating imposed risks and harms, and enhancing human capabilities (Leydens and Lucena, 2014).

Most important to the social justice literature is the concept of power and how power differentials might prevent equitable collaborations between engineers and community members. There is therefore a need to shift power relations, for example, by having humanitarian engineers genuinely take on the roles of learners and recognise their limited knowledge of many aspects of the community, before actually attempting to solve any existing problem (Nieusma and Riley, 2010). Another way to break traditional power relationships is to follow a rights-based approach, which "recognises individuals as actors in their own development instead of viewing them as victims" (Byars et al., 2009, p. 2714). In summary, in order to meaningfully collaborate with community members, engineers need to follow approved research protocols, follow ethical guidelines, and take measures to shift the power dynamic to a more equal level.

\subsection{Principle 4: Building Trusting Relationships}

A number of papers $(n=16)$ discussed the importance of building trusting relationships. This fourth principle is directly related to the previous one as "acting ethically at all times and avoiding decisions that lead to distrust and suspicion" (Hinton et al., 2014, p. 125) is a fundamental factor in promoting trusting relationships between engineers and community members. However, ethical decision-making is not the only factor that contributes to trust. Maintaining equitable relationships that ensure an appropriate distribution of contributions of money, energy, and time amongst all people involved in a project is often associated with higher levels of trust (Aslam et al., 2014; Hinton et al., 2014; Mehta and Mehta, 2011). Other factors that foster trusted relationships include open communication, respect, reciprocity, and transparency (Aslam et al., 2014; Aslam et al., 2013; Chisolm et al., 2014; de Chastonay et al., 2012). Trust appears to be directly related to the time that engineers spend with community members, although it is not clear what minimum time is necessary and what kind of activities may best foster trust (Garff et al., 2013; Hinton et al., 2014; Leydens and Lucena, 2014; Munoz, 2014). Whilst building trust seems to be a very important principle for successful HE projects, the literature we retrieved is limited on this topic and further research is needed to understand more deeply the dynamics of trust.

\subsection{Principle 5: Creating competent multi or inter-disciplinary teams}

Just under half of the papers $(n=22)$ reported on the importance of having diverse team members that can contribute to the technical and social aspects of $\mathrm{HE}$ and similar projects (Jue, 2011; Leydens and Lucena, 2009), by utilising relevant competencies. This is because the nature of the problems addressed in these projects "requires knowledge, skills, and sensitivity in social, political, technical, ecological, and economic factors" (Mattson and Wood, 2014, p. 6). Teams should include members from multiple disciplines, including "sociologists, economists, anthropologists, public health experts" (Amadei et al., 2010, p. 6). For instance, in Dodson and Barbach's (2015) fog water harvesting project in rural Morocco, social scientists played a key role in conducting robust household surveys of water usage, whilst Magoon et al. (2010) relied on a local anthropologist to involve the community in their water supply and treatment project in rural Belize. In summary, engineers and engineering students are strongly advised to deploy "models that successfully blur disciplinary boundaries and decentre engineering as the key expertise in addressing development problems" (Nieusma and Riley, 2010, p. 57).

Furthermore, many articles propose that team members of any HE project must possess fundamental competencies, including appropriate mindsets, cross-cultural skills, and listening skills. Amongst necessary mindsets, Aslam et al. (2014) and Vandersteen et al. (2009) state that a humble mindset and a sense of humility may lead engineers to embrace more cooperative approaches to HE. Byars et al. (2009), Hussain et al. (2012), and Schneider et al. (2008) recognise that the beliefs that engineers hold about underserved communities can hinder or enhance community participation. For instance, Byars et al. (2009) explain that by taking a rights-based approach, engineers will be able to see underserved communities as "actors in their own development instead of viewing them as victims" (p. 2714) who are waiting to be saved by foreigners. In order to develop such a belief about others, engineers also need to acquire high degrees of empathy (Hinton et al., 2014; Leydens and Lucena, 2014; Mattson and Wood, 2014). Specifically, Schneider et al. (2008) suggest that empathy is "crucial to re-envisioning a community not exclusively through the lens of what it lacks, but through its multiple social, cultural, and other assets and capacities, and most of all its own dreams and aspirations" (p. 47).

Competencies such as having a humble mindset, empathy, and unbiased beliefs regarding other people's knowledge, skills, desires, and motivations, are traits that focus on others. However, a few papers also discuss how a focus on self may further promote better interactions with partner communities and especially mitigate power differentials. In order to do so, engineers need to develop a deep awareness of their own pre-existing understandings, assumptions, and unconscious biases as shaped by their own background and prior experiences (Aslam et al., 2014; Hinton et al., 2014; Hussain et al., 2012; Leydens and 
Lucena, 2014; Niesuma and Riley, 2010; Parson, 1996). White (1997) calls this trait "critical self-awareness," which requires that engineers examine and adapt their behaviour both when interacting with community members and when making any decision independently.

Whilst possessing the proper mindset and high levels of critical self-awareness, it is also important to remember that differences in culture, language, and values can affect how engineers collaborate with community members (Avrai et al., 2012; Chisolm et al., 2014; Harshfield et al., 2009; Hussain and Sanders, 2012). For instance, in a project focused on developing prosthetic legs for disadvantaged Cambodian children, Hussain et al. (2012) describe how they changed the way they asked questions to children due to local Buddhist beliefs:

"[A]ccording to Buddhist beliefs, one should never show ingratitude. Consequently, we had to rephrase some questions so that the children would not be worried about criticising. Instead of asking the children what they did not like about the prototypes, for example, we asked them what they really liked about them and what they liked a little less" (p. 99)

Therefore, engineers need to be able to understand how the local beliefs and values may shape interactions and adapt their behaviour to navigate such differences (Garff et al., 2013). Failing to do so could lead to misunderstandings and other harmful consequences.

Finally, Leydens and Lucena (2009) position contextual listening as a key ability for humanitarian engineers. It is important to distinguish contextual listening from basic listening, the latter referring to "hearing or paying attention to the verbal and nonverbal messages of any speaker" and "is framed as a dyadic process of speaking (output) and hearing or receiving information (input)" (Lucena et al., 2010 p. 124). In contrast, contextual listening is a complex, multidimensional, and integrated process where "information such as cost, weight, technical specs, desirable functions, and timeline acquires meaning only when the context of the person(s) making the requirements (their history, political agendas, desires, forms of knowledge, etc.) is fully understood" (Lucena et al., 2010, p. 125). Contextual listening is viewed as so important by Leydens and Lucena (2014) that they include it as a criterion to achieve social justice in HE work.

In summary, humanitarian engineers should seek collaborations with non-technical experts and strive to continually develop high levels of humility, empathy, and critical self-awareness as well as a keen ability to navigate cross-cultural differences and contextual listening skills.
4

\section{CONCLUSION AND \\ RECOMMENDATIONS}

In this paper, we report results from a qualitative content analysis of 49 papers that led to the development of a framework consisting of five principles that can guide humanitarian engineering projects. The proper application of the five guiding principles has the potential to enhance the interactions between humanitarian engineers and community members, and thereby increase the probability that $\mathrm{HE}$ projects will be successful and sustainable. Based on the five principles, we recommend that $\mathrm{HE}$ professionals and educators reflect on the following questions when planning and executing any HE project:

1. Questions related to Principle 1 (local champion):

a. What is your relationship with your local champion? Could it be improved?

b. How are you supporting your champion to build local capacity?

2. Questions related to Principle 2 (local resources and expertise):

a. What resources are available locally?

b. What skills do locals already have?

c. How could you build upon the local expertise rather than bringing external expertise?

3. Questions related to Principle 3 (ethics and social justice):

a. To what extent have you considered ethical issues related to collecting any kind of data from the community?

b. To what extent are you following established professional codes of ethics or other ethical frameworks in every aspect of your project?

c. How are you mitigating power differentials and creating equitable relationships between you and the community members?

d. To what extent are you identifying and a ddressing structural conditions that may give rise to community needs?

4. Questions related to Principle 4 (trusted relationship)

a. How are you going to create trust between you and the community members?

b. To what extent are you offering and maintaining open communication channels?

c. How are you ensuring transparency and reciprocity in your interactions with the community?

5. Questions related to Principle 5 (creating multi or interdisciplinary and competent teams)

a. Have you consulted social science and other non-engineering experts such as anthropologists, 
healthcare professionals, social workers, and/ or others?

b. How diverse is your team and how could you increase its diversity?

c. To what extent does your team possess the competencies (humility, self-awareness, cross-cultural, listening skills, etc.) needed to effectively engage with community members?

The above questions do not have easy answers, but it is important that humanitarian engineers keep them in mind when working on HE projects. Resources to answer such questions can be found in the literature cited in this paper, but we also urge other scholars to further investigate how these guiding principles can be applied and what other principles should be followed. It is also worth noting that traditional engineering degrees do not integrate development of the competencies discussed in Section 3.5. Therefore, we strongly suggest that humanitarian engineers seek alternative training venues to make sure that they develop the needed competencies to engage effectively with community members, including, for instance, new degrees or certificates in humanitarian engineering, short online courses and workshops.

\section{LIMITATIONS AND FUTURE WORK}

We close by acknowledging a few limitations of this study that in turn suggest some areas of opportunity for future work. First, to maintain feasibility of the scope of the study, the literature search was limited to two databases (Compendex and Inspec) with an engineering focus. Therefore, future research could investigate how participation is discussed and studied in other non-engineering disciplines that might be relevant to humanitarian engineering. Second, as our intended audience are university students and educators or professionals working on EWB-type projects, the literature review was limited to small-scale engineering projects and the findings might not be transferrable to larger engineering projects. Future research should explore principles of participation in large-scale projects and compare these findings with smaller-scale projects. Finally, in this research project we looked at participation with a broad lens, and did not address what optimal community participation would look like and how the aforementioned principles may support it. Future work should collect more evidence to understand what levels of community participation are optimal. This line of research should also focus on critical perspectives, including, for instance, discussion of potential participation thresholds (e.g., Mark and Davis, 2012) and the assumption of communities as homogenous social entities (e.g., Guijt and Shah, 1998).

\section{ACKNOWLEDGEMENTS}

We would like to acknowledge the members of the Global Engineering Education Collaboratory (GEEC) research group at Purdue University, along with Professors Robin Adams, Jon Leydens, Alice Pawley, and Carla Zoltowski, for their support of this research study. We also would like to thank the authors of the papers we collected, without which this study would not have been possible. Special thanks also to the two anonymous reviewers and the associated editors that helped us improve the quality of this manuscript.

\section{REFERENCES}

Amadei, B, Sandekian, R, \& Thomas, E 2009, 'A model for sustainable humanitarian engineering projects', Sustainability, vol. 1, no. 4, pp. 1087-1105.

Avrai, J, \& Post, K 2012, 'Risk management in a developing country context: Improving decisions about point-of-use water treatment among the rural poor in Africa', Risk analysis, vol. 32, no. 1, pp. 67-80.

Aslam, A, Navarro, I, Wen, A, \& Hassett, M 2014, 'Stuck in cement: Breaking from conventional mindsets in student-led service learning partnerships', International Journal for Service Learning in Engineering, vol. 9, no. 1, pp. 135-149.

Aslam, A, Pearson-Beck, M, Boots, R, Mayton, H, Link, S, \& Elzey, D 2013, 'Effective community listening: A case study on photovoice in rural Nicaragua', International Journal for Service Learning in Engineering, vol. 8, no. 1, pp. 36-47.

Barb, K, \& Everett, JW 2014, 'Clean water for La Ceiba, El Salvador-Household biosand filters', International Journal for Service Learning in Engineering, vol. 9, no. 1, pp. 40-63.

Byars, P, Woodrow, M, \& Antizar-Ladislao, B 2009, 'Integrated method in international development for water solutions using the rights-based approach', Water Science \& Technology, vol. 60, no. 10, pp. 2713-2720.

Borrego, M, Foster, MJ \& Froyd, JE 2014, 'Systematic literature reviews in engineering education and other developing interdisciplinary fields', Journal of Engineering Education, vol. 103, no. 1, pp. 45-76.

Bowen, J, \& Acciaioli, G 2009, 'Improving the success of "bottom-up" development work by acknowledging the dynamics among stakeholders: A case study from an Engineers Without Borders water supply project in Tenganan, Indonesia', Water Science \& Technology, vol. 60, no. 10 , pp. $279-287$.

Canavate, J, \& Casasus, JM 2010, 'Humanitarian engineering in Spain: Ingenieros sin frontieras', IEEE Technology and Society Magazine, vol. 29, no. 1, pp. 12-19.

Chisolm, R, Gall, ET, Read, R, \& Salas, FR 2014, 'Lessons from a student-led development project in Peru: 
Aligning technical and educational perspectives', International Journal for Service Learning in Engineering, Special Edition, pp. 525-539.

de Chastonay, A, Soni, S, Bugas, M, \& Swap, R 2012, 'Community Driven Development of Rocket Stoves in Rural South Africa' International Journal for Service Learning in Engineering, vol. 7, no. 2, pp. 49-68.

Dodson, LL, \& Bargach, J 2015, 'Harvesting fresh water from fog in rural Morocco: research and impact Dar Si Hmad's Fogwater Project in Aït Baamrane', Procedia Engineering, vol. 107, pp. $186-193$.

Ferrer-Martì, L, Garwood, A, Chiroque, J, Escobar, R, Coello, J, \& Castro, M 2010, 'A community small-scale wind generation project in Peru', Wing Engineering, vol. 34, no. 3, pp. 277-288.

Garff, P, Dahlin, E, Ward, C, \& Lewis, R 2013, 'Analysis of integrated engineering and social science approaches for projects in developing communities', International Journal for Service Learning in Engineering, Special Edition, pp. 137-150.

Garfì， M，\& Ferrer-Martì，L 2011, 'Decision-making criteria and indicators for water and sanitation projects in developing countries', Water Science \& Technology, vol. 64, no. 1 , pp. 83-101.

Goldmann, M 2012, Failure to understand the local context in Admitting Failure Reading Room, Engineers Without Borders Canada, viewed 05 December 2016, http:// www.admittingfailure.com/failure/mattias-goldmann/

Grant, MJ, \& Booth, A 2009, 'A typology of reviews: An analysis of 14 review types and associated methodologies', Health Information Library Journal, vol. 26, no. 2, pp. 91108.

Guijt, I, \& Shah, MK (eds.), 1998, The Myth of Community: Gender Issues in Participatory Development, Intermediate Technology Publications, London.

Harshfield, E, Jemec, A, Makhado, O, \& Ramarumo, E 2009, 'Water purification in rural South Africa: Ethical analysis and reflections on collaborative community engagement projects in engineering', International Journal for Service Learning in Engineering, vol. 4, no. 1, pp. 1-14.

Heil, E, Nengwenani, D, Raedani, A, Gutierrez, V, Nthambeleni, G, Mathoma, K, Brown-Glazner, R, \& Swap, R 2010, 'Student-led, community driven improvement of the drinking supply in a rural village in South Africa', International Journal for Service Learning in Engineering, vol. 5, no. 1, pp. 94-110.

Hinton, A, Ortbal, K, \& Mehta, K 2014, 'The praxis of grassroots diplomacy for social entrepreneurship', International Journal for Service Learning in Engineering, vol. 9, no. 2, pp. 116-134.

Hsieh, H-F, \& Shannon, SE 2005, 'Three approaches to qualitative content analysis', Qualitative Health Research, vol. 15 , no. 9 , pp. $1277-1288$.
Hussain, S 2010, 'Empowering marginalised children in developing countries through participatory design processes', CoDesign, vol. 6, no. 2, pp. 99-117.

Hussain, S, Sanders, EB-N, \& Steinert, M 2012, 'Participatory design with marginalised people in developing countries: Challenges and opportunities experienced in a field study in Cambodia', International Journal of Design, vol. 6, no. 2, 91-109.

Jue, D 2011, 'Improving the long-term sustainability of service-learning projects: Six lessons learned from early MIT ideas competition winners', International Journal for Service Learning in Engineering, vol. 6, no. 2, pp. 19-29.

Landis, JR, \& Koch, GG 1977, 'The measurement of observer agreement for categorical data', Biometrics, vol. 33 , no. 1, pp. 159-174.

Leydens, JA, \& Lucena, JC 2009, 'Listening as a missing dimension in engineering education: Implications for sustainable community development efforts', IEEE transactions on professional communication, vol. 52, no. 4, pp. 359-376.

Leydens, JA, \& Lucena, JC 2014, 'Social justice: A missing, unelaborated dimension in humanitarian engineering and learning through service', International Journal of Service Learning in Engineering, vol. 9, no. 2, pp. 1-28.

Liberati, A, Altman, DG, Tetzlaff, J, Mulrow, C, Gotzsche, PC, Ioannidis, JP, Moher, D 2009, 'The PRISMA statementforreportingsystematicreviewsandmeta-analysesof studies that evaluate healthcare interventions: Explanation and elaboration', BMJ (Clinical Research Education), vol. 339.

Lissenden, J, Maley, S, Mehta, K 2015, 'An era of appropriate technology: Evolutions, oversights, and opportunities', Journal of Humanitarian Engineering, vol. 3, no. 1., pp. 24-35.

Magee, A, Macdonald, R, Johnson, P, Johnson, PW, \& Todd, B. 2011, 'Safe water evaluations in the Peruvian amazon' International Journal for Service Learning in Engineering, vol. 6, no. 1, pp. 104-117.

Magoon, C, Villars, K, Evans, J, Hickey, B, Sayre, A, Tutino, C, \& Swap, RJ 2010, 'Water supply and treatment design in rural Belize: A participatory approach to engineering action research' International Journal for Service Learning in Engineering, vol. 5, no. 1, pp. 47-63.

Marks, SJ, \& Davis, J, 2012, 'Does User Participation Lead to Sense of Ownership for Rural Water Systems? Evidence from Kenya' World Development, vol. 40, no. 8, 1569-1576.

Marsolek, MD, Cummings, PK, Alcantara, JT, Wayne, M, Quinter, LF, Vallejos, C, Jackels, C F, Jackels, SC 2012, 'Wastewater treatment for a coffee processing mill in Nicaragua: A service-learning design project' International Journal for Service Learning in Engineering, vol. 7, no. 1, pp. 69-92. 
Mattson, CA, \& Wood, AE 2014, 'Nine principles for design for the developing world as derived from the engineering literature', Journal of Mechanical Design, vol. 136, no. 12, pp. 1-15.

Mazzurco, A 2016, 'Methods to facilitate community participation in humanitarian engineering projects: Laying the foundation for a learning platform', $\mathrm{PhD}$ thesis, Purdue University.

Mazzurco, A, \& Jesiek BK, 2017, 'Laying the foundations of a learning platform for humanitarian engineering: Methodological approach and results', Proceedings of 2017 American Society for Engineering Education (ASEE) Annual Conference and Exposition, Columbus Convention Centre, Colombus.

Mazzurco A, \& Jesiek, BK 2014, 'Learning from failure: Developing a typology to enhance global service-learning engineering projects', Proceedings of 121st American Society for Engineering Education (ASEE) Annual Conference and Exposition, Indianapolis.

McDaniel, M, Prebil, E, Swap, R, Berinyuy, C, Chapman, D, Eilerts, H, \& McDaniel, J 2011, 'Community-led sanitation in Simoonga, Zambia', International Journal for Service Learning in Engineering, vol. 6, no. 2, pp. 58-77.

Mehta, C, \& Mehta, K 2011, 'A design-space and businessstrategy exploration tool for infrastructure-based ventures in developing communities' International Journal for Service Learning in Engineering, vol. 6, no. 2, pp. 30-57.

Mitcham, C, \& Munoz D 2010, Humanitarian Engineering, Synthesis Lectures on Engineers, Technology and Society, Morgan and Claypool Publishers, San Rafael, CA.

Munoz, DR 2014, 'In search of community; Humanitarian engineers and circles of friends', International Journal for Service Learning in Engineering, Special Edition, pp. 509524.

Murcott, S 2007, 'Co-evolutionary design for development: Influences shaping engineering design and implementation in Nepal and the global village', Journal of International Development, vol. 19, no. 1, pp. 123-144.

Murphy, HM, McBean, EA, \& Faranbakhsh, K 2009, 'Appropriate technology - A comprehensive approach for water and sanitation in the developing world', Technology in Society, vol. 31, pp. 158-167.
Nieusma, D, \& Riley, D 2010, 'Designs on development: Engineering, globalisation, and social justice', Engineering Studies, vol. 2, no. 1, pp. 29-59.

Osnes, B 2013, 'Engaging women's voices through theatre for energy development', Renewable Energy, vol. 49, pp. 185-187.

Paye, S. 2010, 'Ingénieurs Sans Frontières in France: From humanitarian ideals to engineering ethics', IEEE Technology and Society Magazine, vol. 29, no. 1, pp. 20-26.

Parson, LB 1996, 'Engineering in context: Engineering in developing countries', Journal of Professional Issues in Engineering Education and Practice, vol. 122, no. 4, pp. 170-176.

Ramirez, MC, Bengo, I, Mereu, R, Bejerano R, AXB, \& Silva, JC 2011, 'Participative methodology for local development: The contribution of engineers without borders from Italy and Colombia: towards the improvement of water quality in vulnerable communities', Systematic Practice and Action Research, vol. 24, no. 1 pp. 45-66.

Schneider, J, Leydens, JA, \&, Lucena, J 2008, 'Where is 'community'? Engineering education and sustainable community development', European Journal of Engineering Education, vol. 33, no. 3, pp. 307-319

Sianipar, CPM, Yudoko, G, Dowaki, K, \& Adhiutama, A 2013, 'Design methodology for appropriate technology: Engineering as if people mattered', Sustainability, vol. 5 no. 8, pp. 3382-3425.

Third, K, Fun, OM, Bowen, J, Micenko, A, Grey, V, \& Prohasky, T 2009, 'Engineers Without Borders AustraliaLessons learned from an innovative approach to the upgrade of water supply infrastructure in Tenganan, Indonesia', Water Science \& Technology, vol. 59, no. 6, pp. 1201-1207.

Vandersteen, JDJ, Baillie, CA, \& Hall, KR 2009, 'International Humanitarian Engineering: Who benefits and who pays?', IEEE Technology and Society Magazine, vol. 28, pp. 32-41.

White, L, \& Taket, A 1997, 'Beyond appraisal: Participatory appraisal of needs and the development of action (PANDA)', International Journal of Management Science, vol. 25, no. 5, pp. 523-534. 